\title{
Room temperature phosphorescence of 2-bromonaphthalene in SDS rodlike micelles
}

\author{
Wann-Yin Lin *, Jen-How Huang, Jin-Fang Hsu \\ Department of Chemistry, National Taiwan University. Taipei 10764. Taiman
}

Received 23 Octoher 1996; accepted 18 March 1997

\begin{abstract}
Room temperature phosphorescence (RTP) of 2-bromonaphthalene (2-BN) in SDS micelles has been studied in the presence of various salt and surfactant concentrations and at various temperatures. RTP of 2-BN was easily observed in the rodlike micelles of SDS when the added sodium chloride exceeded a certain concentration. The phosphorescence intensity was found to increase sharply during the sphere-torod transition because of the tremendous increase in microviscosity. The intensity declined slightly at very high salt concentration, owing to the formation of flexible rods. At a given salt and surfactant concentration, the phosphorescence intensity decreased drastically with increasing temperature, probably because of the decreased aggregation number and microviscosity of the micelles. Moreover, a smaller value of the second $\mathrm{cmc}$ and a sharper sphere-to-rod transition were observed at higher temperatures. At a given salt concentration (above the second $\mathrm{cmc}$ ) and temperature, the phosphorescence intensity increased steadily with increasing surfactant concentration and leveled off above a certain concentration of SDS. This study proposed a potential use of rodlike micelles as a convenient means of observing the RTP of luminophores with an intrinsic heavy atom. On the other hand, RTP of heavy-atom-containing luminophores may also he used as an alternative probe for detection of the sphere-to-rod transition of micelles. C 1997 Elsevier Science S.A.
\end{abstract}

Keywords: 2-Bromonaphthalene: Rodlike micelle; Room temperature phosphorescence; SDS

\section{Introduction}

Room temperature phosphorescence (RTP) has been observed in the solid state by immobilizing the luminophore on an inert support such as silica gel [1] or filter paper [2]. In a fluid solution, RTP has been observed in organized media such as micelles $[3,4]$, cyclodextrin [5,6], or colloids/ microcrystals [7]. RTP has also been observed for tryptophan buried in the interior of a protein [8]. These media provide a rigid microenvironment for the luminophore and screen it from external quenchers, so facilitating the observation of RTP. Another approach to detection of RTP in a fluid solution is to utilize the sensitized triplet-triplet energy transfer [9]. Because of its simplicity, good selectivity, and high sensitivity, RTP has been applied in the determination of trace amounts of aromatic compounds of biochemical and environmental interest [10] and in HPLC detection [11]. Deoxygenation is crucial for a successful observation of RTP in a fluid solution. A variety of methods, such as purging with nitrogen or reduction with enzymes [11] or sodium sulfite [12], has been used for the removal of dissolved oxygen.

\footnotetext{
* Corresponding author.
}

The presence of a heavy atom to increase the rate of intersystem crossing is also very important for the detection of RTP. Addition of external heavy atoms such as thallium or silver ion in the micellar assembly [3,4] or 1,2-dibromoethane in cyclodextrin $[5,6]$ was indispensible for a successful obscrvation of RTP in these systems.

It is well known that, when the surfactant concentration is above the critical micelle concentration $(\mathrm{cmc})$, the surfactant molecules aggregate to form spherical micelles. At high surfactant concentration and in the presence of a strong electrolyte, micelles may grow from a spherical shape to a rigid rod, then to a flexible rod, and then entangle with each other. The sphere-to-rod transition has been observed by a wide variety of methods such as light scattering [13,14], viscosity [15], ultrasonic absorption [16], small angle neutron scattering [17], and calorimetry [18]. This transition is usually accompanied by a dramatic increase in microviscosity and hydrophobicity of the micelles. The increased rigidity and decreased dynamic quenching for rodlike micelles is expected to facilitate the observation of RTP, similarly to the utilization of the glassy state at $77 \mathrm{~K}$ for measuring phosphorescence in the early days. In this paper, we will study the RTP of 2-bromonaphthalene (2-BN, a luminophore with an 
intrinsic hcavy atom) during the sphere-to-rod transition in SDS micelles induced by the addition of sodium chloride. The effects of temperature and of surfactant and salt concen trations on the phosphorescence intensity of 2-BN will also be investigated.

\section{Experimental details}

SDS ( sodium dodecyl sulfate, Sigma), 2-BN (Aldrich), sodium chloride (Fluka) and sodium sulfite (Wako) were used without further purification. Deoxygenation was carried out by adding a sufficient amount of sodium sulfite $(>0.01$ $\mathrm{M})$ to the aqueous solution containing appropriate amounts of SDS, $\mathrm{NaCl}$ and $2-\mathrm{BN}$ in a quartz cuvette. The solution was then stirred for $20 \mathrm{~min}$ to remove dissolved oxygen. Deionized water with a specific resistance of $18 \mathrm{M} \Omega \mathrm{cm}^{-1}$ obtained from a Milli-Q system (Millipore) was used in this study. The fluorescence and phosphorescence spectra were recorded on an F-4500 fluorescence spectrophotometer (Hitachi) equipped with a circulating water bath for temperature control. This instrument can be operated in either the fluorescence or the phosphorescence mode. The excitation wavelength was $280 \mathrm{~nm}$; the slit widths for the excitation and emission monochromators were $10 \mathrm{~nm}$ and $5 \mathrm{~nm}$, respectively.

\section{Results and discussion}

\subsection{RTP of 2-BN at various salt concentrations}

Fig. 1(A) shows the fluorescence and phosphorescence spectra of $10^{-5} \mathrm{M} 2-\mathrm{BN}$ at several salt concentrations in 0.05 $\mathrm{M} \mathrm{SDS}, 0.05 \mathrm{M} \mathrm{Na}_{2} \mathrm{SO}_{3}$ aqueous solution at $30{ }^{\circ} \mathrm{C}$. The phosphorescence spectra exhibited two well-resolved bands centered around 490 and $520 \mathrm{~nm}$, respectively. The fluorescence band was centered at $343 \mathrm{~nm}$. The positions of both the fluorescence and the phosphorescence maxima did not shift with increasing salt concentration. The dependence of phosphorescence intensity (measured at $520 \mathrm{~nm}$ ) on $\mathrm{NaCl}$ concentration is depicted in Fig. 1(B). In the absence of $\mathrm{NaCl}$, no RTP of 2-BN was observed. The surfactant concentration used in this study was already above the cmc of SDS ( $\mathrm{cmc}=1.5 \mathrm{mM}$ at $25^{\circ} \mathrm{C}, 0.1 \mathrm{M} \mathrm{NaCl}$; the cmc showed little variation from $25^{\circ} \mathrm{C}$ to $35^{\circ} \mathrm{C}$ but decreased dramatically with increasing salt concentration [19]) indicating the absence of RTP for 2-BN in spherical micelles. The appearance of RTP for 2-BN occurred when the concentration of $\mathrm{NaCl}$ was above $0.2 \mathrm{M}$ (Fig. 1(B)); its intensity increased rapidly with increasing salt concentration and reached a maximum at a salt concentration around $0.35 \mathrm{M}$. It is known that shielding of the charged surfactant molecules with a counterion by the addition of a strong electrolyte reduces their repulsion and causes an elongation on both ends of the micelles leading to the formation of rodlike micelles. The formation of rodlike micelles is usually accompanied by a dramatic increase in
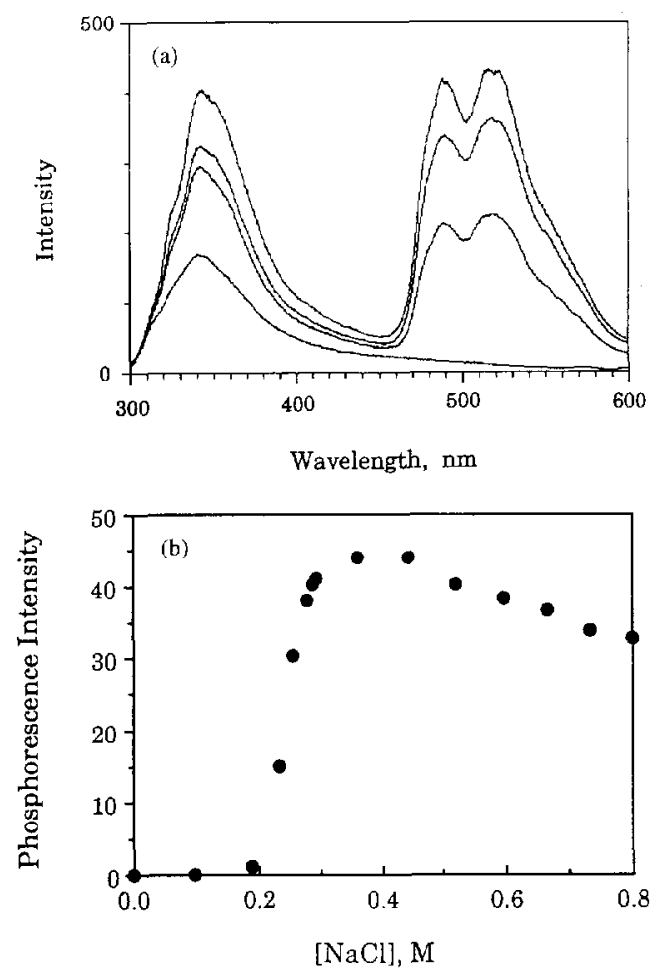

Fig. 1. (A) The fluorescence and phosphorescence spectra $\left(\lambda_{c x}=280 \mathrm{~nm}\right.$, using the fluorescence mode) of $10^{-5} \mathrm{M} 2-\mathrm{BN}$ at $30^{\circ} \mathrm{C}$ in $0.05 \mathrm{M}$ SDS, $0.05 \mathrm{M} \mathrm{Na}_{2} \mathrm{SO}_{3}$ solution containing (from bottom to top) $0,0.25,0.27$ and $0.30 \mathrm{M} \mathrm{NaCl}$. (B) The effect of $\mathrm{NaCl}$ concentration on the phosphorescence intensity (at $520 \mathrm{~nm}$, using the phosphorescence mode) of $10^{-5} \mathrm{M} 2-\mathrm{BN}$ in $0.05 \mathrm{M} \mathrm{SDS}, 0.05 \mathrm{M} \mathrm{Na}_{2} \mathrm{SO}_{3}$ solution at $30{ }^{\circ} \mathrm{C}$

aggregation number $[19,20]$, hydrophobicity [20] and microviscosity [21]. The nonpolar luminophore will probably be located near the central hydrophobic region, excluding the external quenchers and experiencing a tremendous increase in microviscosity. This will provide an environment for a successful observation of RTP, just as the use of the glassy state at $77 \mathrm{~K}$ for measuring the phosphorescence. The added strong electrolyte must exceed a certain critical concentration (called the second $\mathrm{cmc}$ ) for an effective shielding of the charged surfactant molecules to form rodlike micelles. The value of the second cmc depends on the surfactant concentration, the type of counterion and the temperature. According to the report of Lianos and Zena [20], the increase in aggrcgation number $(n)$ was relatively small at lower salt concentration and became very large at higher salt concentration, suggesting a substantial change in the micellar shape above the second cmc. The variation of the phosphorescence intensity of 2-BN in the concentration range $0.2-0.35 \mathrm{M} \mathrm{NaCl}$ may thus correspond to the sphere-to-rod transition. The second cmc of SDS was reported to be in the range $0.40-0.45$ $\mathrm{M} \mathrm{NaCl}$ at $25^{\circ} \mathrm{C}[18-20]$. In this study, the second $\mathrm{cmc}$ corresponding to the first appearance of RTP was $0.30 \mathrm{M}$ (including the contribution of sodium ion from sodium sulfite) at $30^{\circ} \mathrm{C}$.

Further addition of $\mathrm{NaCl}$ caused a steady increase in aggregation number. At high $\mathrm{NaCl}$ concentration, the aggregation number becomes very large (e.g., $n \approx 1630$ at $0.80 \mathrm{M} \mathrm{NaCl}$ 
for SDS in aqueous solution at $25^{\circ} \mathrm{C}$ [19]). Continuing elongation on both sides of the rodlike micelles upon further addition of $\mathrm{NaCl}$ gives rise to flexible rods. If the cylindrical micelles grow too long they may entangle with each other. This type of transition has been observed for the alkyltrimethylammonium halide micelles [22,23]. The decrease in intensity for the RTP of $2-\mathrm{BN}$ at high $\mathrm{NaCl}$ concentration (Fig. 1(B)) is probably due to the increased microfluidity upon formation of the flexible rods. The fluorescence intensity, on the other hand, showed a steady increase upon addition of $\mathrm{NaCl}$ and leveled off at $\approx 0.4 \mathrm{M} \mathrm{NaCl}$ (data not shown).

\subsection{Temperature dependence of RTP of 2-BN}

Fig. 2(A) shows the fluorescence and phosphorescence spectra of $10^{-5} \mathrm{M} 2-\mathrm{BN}$ in $0.05 \mathrm{M}$ SDS, $0.6 \mathrm{M} \mathrm{NaCl}, 0.05$ $\mathrm{M} \mathrm{Na}_{2} \mathrm{SO}_{3}$ aqueous solution from $20{ }^{\circ} \mathrm{C}$ to $60^{\circ} \mathrm{C}$. The fluorescence intensity varied only slightly, whereas the phosphorescence intensity decreased dramatically as the temperature increased. The temperature dependence of the phosphorescence intensity (measured at $520 \mathrm{~nm}$ ) of $2-\mathrm{BN}$ is given in Fig. 2(B). A linear relationship was observed between the logarithm of the phosphorescence intensity and the absolute temperature. Similar linear relationships were also observed
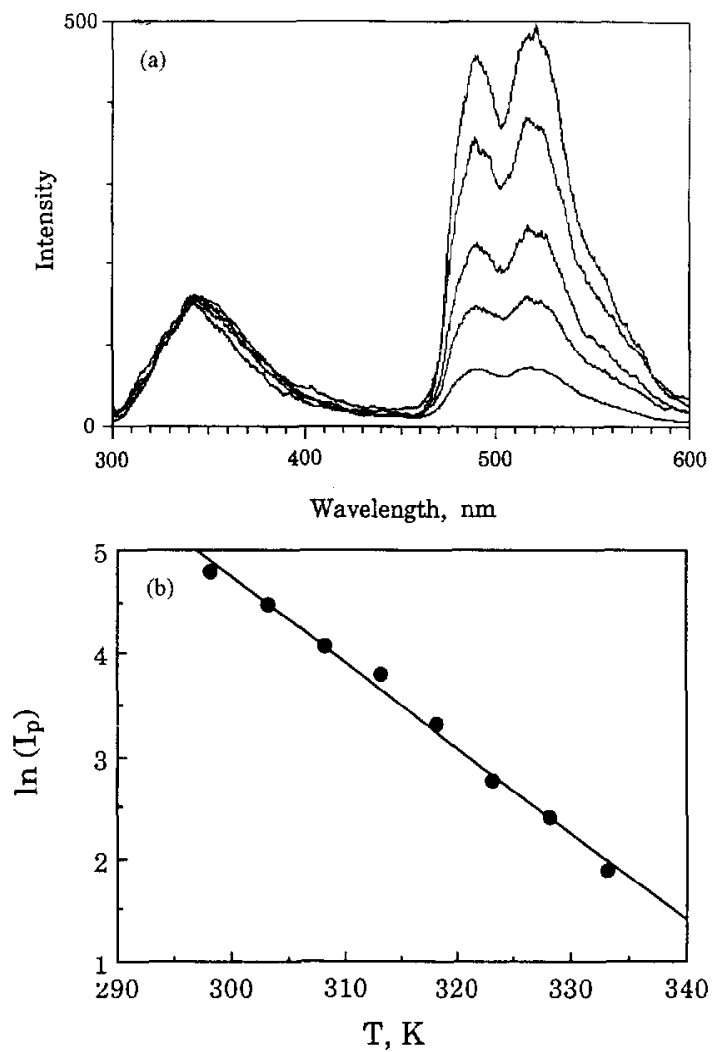

Fig. 2. (A) The fluorescence and phosphorescence spectra $\left(\lambda_{\mathrm{ex}}=280 \mathrm{~nm}\right.$, fluorescence mode) of $10^{-5} \mathrm{M} 2-\mathrm{BN}$ in $0.05 \mathrm{M} \mathrm{SDS}, 0.6 \mathrm{M} \mathrm{NaCl}$ and 0.05 $\mathrm{M} \mathrm{Na}_{2} \mathrm{SO}_{3}$ solution at (from top to bottom) $20,30,40,50$ and $60^{\circ} \mathrm{C}$. (B) Plot of the logarithm of the phosphorescence intensity $\left(I_{\mathrm{p}}\right.$, measured at 520 $\mathrm{nm}$; phosphorescence mode) of $10^{-5} \mathrm{M}$ 2-BN in $0.052 \mathrm{M}$ SDS, $0.05 \mathrm{M}$ $\mathrm{Na}_{2} \mathrm{SO}_{3}$ solution against $T$.

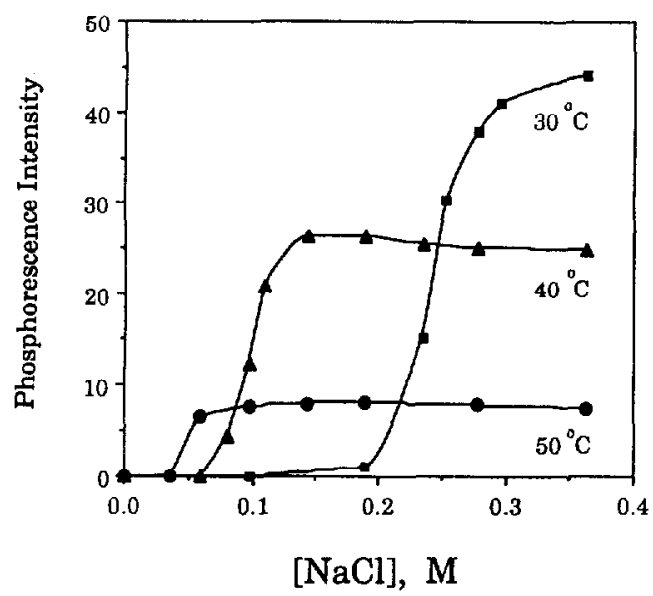

Fig. 3. The variation of the phosphorescence intensity (at $520 \mathrm{~nm}$, phosphorescence mode) of $10{ }^{5} \mathrm{M}$ 2-BN in 0.05 $\mathrm{M}$ SDS and $0.05 \mathrm{M} \mathrm{Na}_{2} \mathrm{SO}_{3}$ solution as a function of $\mathrm{NaCl}$ concentration at 30,40 and $50{ }^{\circ} \mathrm{C}$. The data at $60^{\circ} \mathrm{C}$ were not included because of the extremely weak intensities in the phosphorescence mode.

at other salt concentrations above the second cmc (data not shown ). Hayashi and Ikeda [19] have reported a linear relationship between the logarithm of the apparent molccular weight (i.e., the aggregation number) and the temperature. These results suggest that there is a linear correlation between the phosphorescence intensity and the aggregation number at a given salt concentration. As the temperature decreases, the mobility of the surfactant molecule tends to decrease. The less flexible neighboring surfactant molecules may have better contact with each other and therefore are more easily and tightly (and hence densely) packed. This may lead to an increase in aggregation number and rigidity of the micelles and also to an enhancement of the phosphorescence quantum yield of the luminophore. The large temperature effect on the aggregation number (e.g., $n \approx 1630$ and 909 for SDS at 25 ${ }^{\circ} \mathrm{C}$ and $35^{\circ} \mathrm{C}$, respectively [19]) and the phosphorescence intensity (Fig. 2(B)) is probably due to there being multiple points of contact for the long dodecyl group, similar to the cooperative folding of a protein from a random-coil polypeptide chain. The interactions that stabilize a folded protein are individually weak. However, when they occur simultaneuusly, the protein is folded within seconds. Similarly, the combination of many small stabilization energies (due to lowering of the tempcrature) from cach individual point of contact between surfactant molecules may lead to a tremendous stabilization effect.

Fig. 3 shows the dependence of the phosphorescence intensity of $10^{-5} \mathrm{M} 2-\mathrm{BN}$ in $0.05 \mathrm{M}$ SDS and $0.05 \mathrm{M} \mathrm{Na}_{2} \mathrm{SO}_{3}$ aqueous solution on the salt concentration at 30,40 and 50 ${ }^{\circ} \mathrm{C}$. Data at $20^{\circ} \mathrm{C}$ were not obtained because of the poor solubility of SDS at low salt concentrations. The results indicated a smaller second cmc (estimated from the first appearance of RTP) and a sharper sphere-to-rod transition at higher temperatures. The half-transition points (including the sodium ion from sodium sulfite) at 30,40 and $50{ }^{\circ} \mathrm{C}$ were $0.35,0.20$ and $0.14 \mathrm{M}$, respectively. A decrease in the second cmc with increasing temperature has also been reported for 


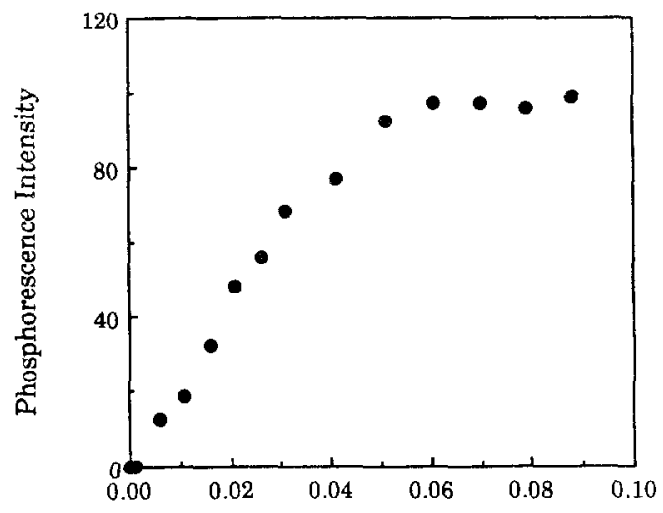

[SDS], M

Fig. 4. The change of the phosphorescence intensity (at $520 \mathrm{~nm}$, phosphorescence mode) of $10^{-5} \mathrm{M} 2-\mathrm{BN}$ at $30^{\circ} \mathrm{C}$ in $0.5 \mathrm{M} \mathrm{NaCl}$ and $0.05 \mathrm{M} \mathrm{Na}_{2} \mathrm{SO}_{3}$ solution as a function of SDS concentration.

the alkyltrimethylammonium bromide system [23]. A decline in phosphorescence intensity due to the formation of flexible rods at high salt concentrations was observed at all temperatures studied (data not shown).

\subsection{Dependence of RTP of 2-BN on SDS concentration}

Fig. 4 shows the changes in phosphorescence intensity of $10^{-5} \mathrm{M} 2-\mathrm{BN}$ at $30^{\circ} \mathrm{C}$ in $0.5 \mathrm{M} \mathrm{NaCl}, 0.05 \mathrm{M} \mathrm{Na}_{2} \mathrm{SO}_{3}$ aqueous solution at various SDS concentrations. The phosphorescence intensity increased with increasing SDS concentration and leveled off at $0.06 \mathrm{M}$ SDS. Hayashi and Ikeda [19] have reported an increase in aggregation number with increasing surfactant concentration. Since the phosphorescence intensity is linearly correlated with the aggregation number in some cases, as discussed in Section 3.2, the enhanced phosphorescence intensity with increasing surfactant concentration is probably due to the increased aggregation number and microviscosity of the micelles. At high surfactant concentrations ( $>0.06 \mathrm{M}$ ), however, a saturation of the aggregation number (or microviscosity) occurred and the phosphorescence intensity reached a plateau.

\section{Conclusion}

RTP of 2-BN was easily observed in rodlike micelles of SDS. The phosphorescence intensity was found to be strongly dependent on the salt and surfactant concentrations and on the temperature. The phosphoreseence intensity increased sharply during the sphere-to-rod transition because of a tremendous increase in microviscosity. The intensity declined slightly at very high salt concentration owing to the formation of flexible rods. At a given salt and surfactant concentration, the phosphorescence intensity decreased dramatically with increasing temperature, probably because of the decreased aggregation number and microviscosity of the micelles.
Morcover. a smaller value of the second cme (estimated from the first appearance of RTP) and a sharper sphere-to-rod transition were observed at higher temperatures. At a given salt concentration (above the second $\mathrm{cmc}$ ) and temperature, the phosphorescence intensity increased steadily as the surfactant concentration increased and leveled off above a certain concentration of SDS. The maximal intensity of RTP for $2-\mathrm{BN}$ in rodlike micelles at $30^{\circ} \mathrm{C}$ was observed in $0.06 \mathrm{M}$ SDS, $0.04 \mathrm{M} \mathrm{NaCl}$, and in the presence of a sufficient amount ( $>0.01 \mathrm{M}$ ) of sodium sulfite for complete deoxygenation. This study has proposed the potential use of rodlike micelles as a convenient means of observing the RTP of a luminophore with an intrinsic heavy atom. On the other hand, RTP of the heavy-atom-containing luminophore may also be used as an alternative probe for monitoring the sphere-to-rod transition of nicelles.

\section{Acknowledgements}

The authors thank the National Science Council, Republic of China, for financial support (Grant No. NSC-85-2113-M002-011).

\section{References}

[1] M.J. Roth. J. Chromatogr. 30 (1967) 276.

[2] C.D. Ford, R.J. Hurtubise, Anal. Chem. 52 (1980) 656.

[3] L..J. Cline Love. M. Skrilec. I.G. Harbata, Anal. Chem. 52 (1980) 754.

141 M. Skrilec, L.J. Cline Love, Anal. Chem. 52 ( 1980) 1559.

$15]$ S. Seypinski, L.J. Cline Love, Anal. Chem. 56 (1984) 322.

(6) S. Scypinski, L.J. Clinte Luve, Anat. Chenit. 56 (1984) 331.

[7] R. Weinberger, L.J. Cline Love. Spectrochim. Acta Part A 40 (1984) 49

[8] J.M. Vanderkooi, D.B. Calhoun. S.W. Englander, Science 236 (1987) 568.

19| J.J. Donkerbroek, C. Gooijer, N.H. Velthorst, R.W. Frei, Anal. Chem. 54 (1982) 891 .

[10] T. Vo-Dinh, Room Temperature Phosphorimetry for Chemical Analysis, Wiley, New York, 1984.

[11] J.J. Donkerbroek, N.J.R. Van Eikema Hommes, C. Gooijer, N.H. Velthorst, R.W. Frei, J. Chromatogr. 255 (1983) 581.

[12] M.E. Diaz Garcia, A. Sanz-Medel Anal. Chem. 58 (1986) 1436

1131 P.J. Missel, N.A. Mazer, G.B. Benedek, Y. Young, M. Carey, J. Phys. Chen. $84(1980) 1044$

| 14$]$ G. Porte, J. Apell, J. Phys. Chem. 85 ( 1981 ) 2511.

[15] S. Ozcki, T. Ikeda, J. Colloid Intertace Sci. 77 (1980) 219

[16] R. Zielinski, S. Ikeda, H. Nomuar, S. Kato, J. Colloid Interface Sci. 125 (1988) 497.

[ 17] S.S. Berr, R.R. Jones, Langmuir 4 (1988) 1247.

[18] D. Nguyen, G. Bertrand, J. Phys. Chem. 96 ( 1992) 1994.

[19| S. Hayashi, S. Ikeda, J. Phys. Chem. 81 (1980) 711.

[20] P. Lianos, R. Zena, J. Phys. Chem. 84 (1980) 3339.

121 ] S. Miyagishi, T. Asakawa, M. Nishida, J. Colloid Interface Sci. 115 (1987) 109

[22] W. Binana-Limbele, R. Zana. J. Coiloid Interface Sci. 121 ( 1988 ) 81.

[23] S. Miyagishi, H. Kurimoto. T. Asakawa, Bull. Chem. Soc. Jpn. 68 (1905) 135 